\title{
Towards Reconfigurable Digitalized and Servitized Manufacturing Systems: Conceptual Framework
}

\author{
Xavier Boucher ${ }^{1}$, Audrey Cerqueus ${ }^{1}$, Xavier Delorme ${ }^{1}$, Clemens Gonnermann $^{2}$, \\ Magdalena Paul ${ }^{2}$, Gunther Reinhart ${ }^{2}$, Julia Schulz ${ }^{2}$, Fabian Sippl ${ }^{2}$ \\ ${ }^{1}$ Mines Saint-Etienne, Université Clermont Auvergne, CNRS, UMR 6158 LIMOS-Institut \\ Fayol, 158 Cours Fauriel, F-42023 Saint Etienne France \\ ${ }^{2}$ Institute for Machine Tools and Industrial Management ( $\left.i w b\right)$, Technical University of \\ Munich, Boltzmannstraße 15, 85748 Garching, Germany
}

\begin{abstract}
Based on an analysis of research and industrial trends, the paper introduces the basis of a conceptual research framework for an innovative methodology dedicated to design, implement and manage Reconfigurable Manufacturing Systems (RMS). The authors present key challenges extracted from the literature and key industrial needs for RMS, drawn from expert interviews via an industry study. A conceptual framework for reconfigurability management is proposed, which opens several avenues for future research.
\end{abstract}

Keywords: Reconfigurability, Industry 4.0, Servitization, Digitalization.

\section{Introduction}

Dynamic product/service life-cycles, globalization and shortage of resources are megatrends with a strong impact on production management. The industry is forced to high customization, inducing a clear increase in production complexity. Flexible and reconfigurable production lines intend to answer these challenges [1]. The adaptability of Reconfigurable Manufacturing Systems (RMS) aims at reducing reconfiguration time, effort and costs, through proactive adjustment of the production system and its correlating processes, with minimal effort for a specific product family [1]. Current approaches still do not cope with the full RMS complexity. Besides the hardware and software complexity, which induces production downtimes, many different production processes are affected [2]. Responsiveness to changes requires highly modular systems, with easily interoperable resources and reconfigurable organizations.

The research approach presented in this paper consists of analyzing both research trends and industrial needs, then use these results as key inputs to structure a proposal for a conceptual framework for an innovative reconfigurability management methodology. The structure of the paper follows this approach, with the two following sections providing respectively (i) literature survey on RMS and (ii) the results of an industrial requirements analysis. Section 4 presents the conceptual framework proposed, with the explanation of key concepts (conceptual basis of the framework), then the description of the overall structure of the framework. Section 5 underlines the main perspectives. 


\section{Current trends on Reconfigurable Manufacturing Systems}

\subsection{Key Concepts for Reconfigurable Manufacturing Systems}

The idea of Reconfigurable Manufacturing System (RMS), first introduced in [3], was formally defined by Koren et al. [4]. Based on modular components, these systems are designed to support changes in their physical configuration in order to be more responsive to the quick transformations of product demand. The main features of a RMS are:

- Modularity: in a RMS, all the major components should be modular (system, software, control, machines and process, conveyors). Selection of basic modules and the way they can be connected provide systems that can be easily integrated, diagnosed, customized, and converted.

- Integrability: new modules can be easily integrated within the system to extend its capabilities and their integration rules must be established.

- Scalability: possibility to adjust the production capacity to the actual demand by adding or removing resources.

- Customization: this type of system is open-ended and provides customized flexibility for a particular part family.

- Convertibility: ability to switch from a configuration to another and quick system adaptability for future products.

- Diagnosability: detection of machine failure and identification of the root causes of unacceptable part quality to allow a quick correction.

Contrary to Flexible Manufacturing Systems (FMS), which are usually designed for a large family of products, RMS are usually considered when there is little knowledge on future production volume or product changes. If globalization increased the unpredictability of market and as a consequence the need for more responsive production systems, recent studies highlighted the numerous opportunities associated with the new technologies of Industry 4.0 and of Artificial Intelligence in the development of RMS [5]. Beside the technological aspects, research works on RMS also considered the organization of RMS as a whole in order to optimize its performance. Two main questions are emphasized in the literature:

- What do RMS change in the design of production systems and how to define an efficient process to do it $[6,7]$ ?

- How to properly evaluate the capacities of different possible configurations of RMS [8, 9]?

Additionally, reconfigurability management needs to integrate the latest advances on manufacturing systems for the Factory of the Future (FoF), as underlined just below.

\subsection{New Challenges for Reconfigurability Management}

Within the framework of FoF the 3 following challenges should notably be considered.

Digital Control of Production Systems. The rise of communication and information technology has a strong influence on production technology. Digital Twins, providing the virtual representation of real manufacturing components play a central role in the digitalization of production systems [10]. It can provide autonomous decision making and control on the production [11]. Furthermore, as key technology of digitalized 
production, Cyber Physical Systems (CPS) are defined as integrations of computation and physical processes [12]. CPS are enhanced mechatronic systems. An increased decentralization and autonomy in order to achieve higher efficiency and transparency in production systems are the key factors [13]. CPS possess the ability of selfdescription, so that information about its own state and individual functionalities is available. The ability of CPS to communicate among themselves generates an overall Cyber Physical Production System (CPPS) supporting the overall reconfigurability.

Servitization and RMS. Service-oriented strategies have been progressively transforming industrial business models over the last decade, notably with the emergence of so-called Product-Service-Systems (PSS) which gather product and service components within an integrated added-value offer [14]. This new type of business model is currently spreading in B2B applications, typically for innovative manufacturing solutions. A large potential of services (performance traceability, maintenance, upgradability...) can be delivered along the life-cycle of manufacturing technologies to increase the added-value delivered to the customer [15]. This is a key issue for RMS: depending on the deepness of the reconfiguration, distinct levels of services can be required, with strong challenges in balancing new economic models [16] and managing the risks of provider-customer relationship. To the best of our knowledge, servitization strategies have not been integrated in RMS until now.

Sustainability through reconfigurability. Research on the connection between sustainability and reconfigurability remains recent $[17,18]$. Sustainable manufacturing is defined as 'The creation of manufactured products that use processes that minimize negative environmental impacts, conserve energy and natural resources, are safe for employees, communities and consumers and are economically sound' [19]. Creating sustainable manufacturing systems can be facilitated by considering reconfigurability as a new strategy [20]. Challenges in environmental performance and energy consumption can be addressed in industrial companies through the use of RMS [18, 21].

\section{Industrial Requirements for RMS}

\subsection{Introduction: Qualitative Analysis of Industrial Requirements}

Semi-structured interviews with 15 industry experts of eight different companies were conducted following the approaches of [22]. Their aim was to better understand the industry requirements for RMS. All interviewees are representatives of companies which assured their contribution to the underlying research project. Five out of eight companies are engaged in the mechanical engineering sector, two in the automotive sector and one interview partner is a state authority. The interviewees covered different functionalities ranging from upper management to technical development as well as production planners and personnel directly responsible for production lines. Two companies in the mechanical engineering sector consider themselves as sellers of RMS, four companies can be classified as users and two interview partners are not directly involved in developing nor using RMS. Five of the interviewed companies employ over 500 people and can therefore be considered as large companies, whereas two companies 
are mid-sized with a number of employees between 40 and 50. Thus, the selected companies and experts cover a broad range of industry interests and perspectives.

\subsection{Qualitative Evaluation of the Interviews Concerning New Challenges}

Sustainable Reconfigurability. The interviews showed that there are still multiple hurdles which prevent an increase of reconfigurability in production. The majority of answers focused on the technical problems during implementation and operation of RMS. The machines currently offered do not fulfil the level of modularity and flexibility the companies would wish for. The adaptation of the existing production lines can be challenging and e.g. induce downtimes and unintentional influences. Besides this technical perspective, the economic consideration of reconfigurability is also proving difficult. The determination of the most sustainable trade-off between flexibility, controllability and efficiency represents a major challenge. The fact that no specific metrics are able to describe the degree of reconfigurability contributes to this problem. Another topic, which was repeatedly mentioned, was the challenges and problems which workers have to face in a reconfigurable environment. They might feel overwhelmed by the uncertainty imposed by the constant changes in equipment, planning and required skills. However, the interviews also indicated a high level of interest to deal with the topic of reconfigurability which is mainly driven by economic factors. It was stated several times that more flexible production systems are necessary to efficiently control the growing complexity. RMSs are therefore seen as a promising means to increase productivity and thus financial sustainability. Additionally, one company stated that their motivation is to ensure an optimal integration of human workers in the challenging future production environment, as workers are considered as the most important and most flexible production resource available. Consequently, the better integration of human workers and their knowledge into production was also discussed as a potential solution to overcome the hurdles of introducing RMS. Possible solutions to reach this goal are to keep the workers informed through standardized interfaces, as well as a continuous integration in the planning process. The answers also revealed that an effective change management is seen as a key factor to allow a more efficient handling of changes. It can be concluded that the interviewees especially highlighted the economic and socials aspects of reconfigurability, whereas the ecological aspects were only covered marginally. Nevertheless, the ecological potential of RMS must also be taken into account, as described in chapter 2.2.

Digitalization. The conducted interviews concerned the opportunities and risks of digitalization with regard to RMS. It could be observed that small and larger companies deal with the arising changes. The automation of repetitive tasks or the traceability of products are only two mentioned advantages of digitalized RMS. Nevertheless, there are several challenges occurring. Whereas software implementation and the interoperation between different tools only seems to be an issue for large companies with high degree of automation, human aspects are very important for almost all respondent companies. The need of a new employee's skillset is observed. Furthermore, digitalization processes are often difficult to introduce because of doubts or even fears among the employees. In addition to human aspects, data processing is an existing 
problem in most cases. A lack of focused analysis of the increasing amount of acquired data is mentioned. In comparison to the occurring challenges, the interviewed companies recognize several advantages of digitalized RMSs. Increased productivity and reduced production costs are expected. Besides that, the improvement of working conditions is another promising opportunity. Especially the large companies surveyed are already developing solutions in order to exploit the observed advantages. The interviews showed that useful solutions in any kind of application should be modular, standardized and interoperable. If these requirements are met, machine-to-machine communication can be improved, the implementation of new software tools can be abbreviated and methods of artificial intelligence can be applied. The benefits of approaches such as predictive maintenance, process bottleneck detection or digital machine twins have been recognized especially in the larger companies. In addition to the technical requirements, the solutions should be suitable for employees, which requires recurrent teaching as well as user-friendly operation.

Servitization. Six of the interviewed companies are familiar with the concept of servitization, where it is used for different reasons and stages of the life-cycle. In one case, servitization allows more accurate previsions on the demand and thus enables the company to reduce stock and losses. Another company uses servitization as a marketing instrument to highlight their offers and increase demand. As changes in the production system are often customer-driven, the modular concept that can go along with servitization is an asset for two of the interview partners. Offering a service instead of a product can decrease time needed for adaptation, as stated by one interviewee. Servitization can create a stronger relationship between user and provider. For two companies, service models are an important purchase factor. One of those stated, that fast maintenance and constant availability of service are important purchase factors for them. For another company, the possibility to integrate predictive maintenance as a service in their system is crucial. One company stated that, at the moment, very little interest in servitization exists among their customers, as they are not used to rent machines and do not see any advantages. Another interviewee added that, at the moment, services are only considered at design time but not in the production system. For some of the interview partners, there is still potential to increase the usage of servitization models.

\section{Conceptual Basis for RDS Production Systems}

\subsection{Concept of RDS Production Systems}

Two structural dimensions of manufacturing technologies appear as critical for future innovations on reconfigurability: digitalization and servitization. This leads us to define below the notion of Reconfigurable Digitalized and Servitized Manufacturing Systems.

Digitalization is a usual and intrinsic component of reconfigurability. Digitalization embeds several key manufacturing issues, notably (i) to manage the interoperability among interconnectable production components and software solutions; (ii) to increase the efficiency and added-value of digital twin models; (iii) to integrate artificial 
intelligence techniques and mathematical optimization to improve reconfiguration decision-making processes. Digitalization still requires strong advances on data capture (technological digitalization), information management (consistency and added-value of production information), and knowledge management (decision-making use).

Servitization has not been addressed until now in the context of RMS. It involves to integrate reconfigurability management within a service-oriented framework, leading to new business models. The question is no more to sell a technology to a client, but to manage the full life-cycles of the technology implementation, utilization, reconfiguration and, when necessary, retirement. Servitization is not a technological change, but a change of mindset and management relationship applied to the relationship between technology providers and manufacturers. Together with the capacity to design and implement new service packages, key challenges concern the capacity to anticipate and prove the economic advantages for all stakeholders, and to manage the risks induced by service contracts. Servitization adds a new dimension to support reconfigurability, making the link between production system configuration and business model selection. In the approach proposed, manufacturing systems become Smart Manufacturing Product-Service-Systems, where digitalization is a key way to enlarge drastically the service offer provided to manufacturers, while the technology providers find key solutions to increase the efficiency and quality of services and reduce the service costs. Reconfigurability management is very context dependent. In this perspective, this approach aims at developing new abilities to ensure a high level of reconfigurability, adapted to the internal needs, skills and abilities of each manufacturing company.

\subsection{Overview of Conceptual Framework for Reconfigurability Management}

Referring to this concept of RDS Manufacturing Systems, our objective is to propose, a research framework resulting into a methodology for reconfigurability management. This framework is based on the following three key pillars (fig. 1):

1. Life-cycle management applied to manufacturing systems is at the heart of reconfigurability management. Our ambition is to structure, within this methodological framework, the various decision processes and Decision Support Systems contributing to a full life-cycle management of RMS.

2. Uncertainty management is a key transversal approach, fully required at various levels of life-cycle management. The potential of uncertainty modelling and assessment can be increased by the added-value of digitalization at all levels of manufacturing systems, together with current advances on artificial intelligence and optimization techniques.

3. In the context of Factory of the Future, agility of production systems has to be managed while maintaining a higher-level strategy of sustainability. We consider that reconfigurability management is meant at achieving a higher degree of sustainability for production systems. This induces that sustainable objectives should be defined at all decision levels contributing to life-cycle management.

This leads us to structure the framework, with four decision levels of life-cycle management, each of which can be supported by several decision-aid methods or tools, constituting the so called 'Toolbox for the reconfigurability and life-cycle management 
of RDS Manufacturing Systems'. Digitalization and servitization are integrated as two transversal dimensions, to be integrated at every level of the toolbox.

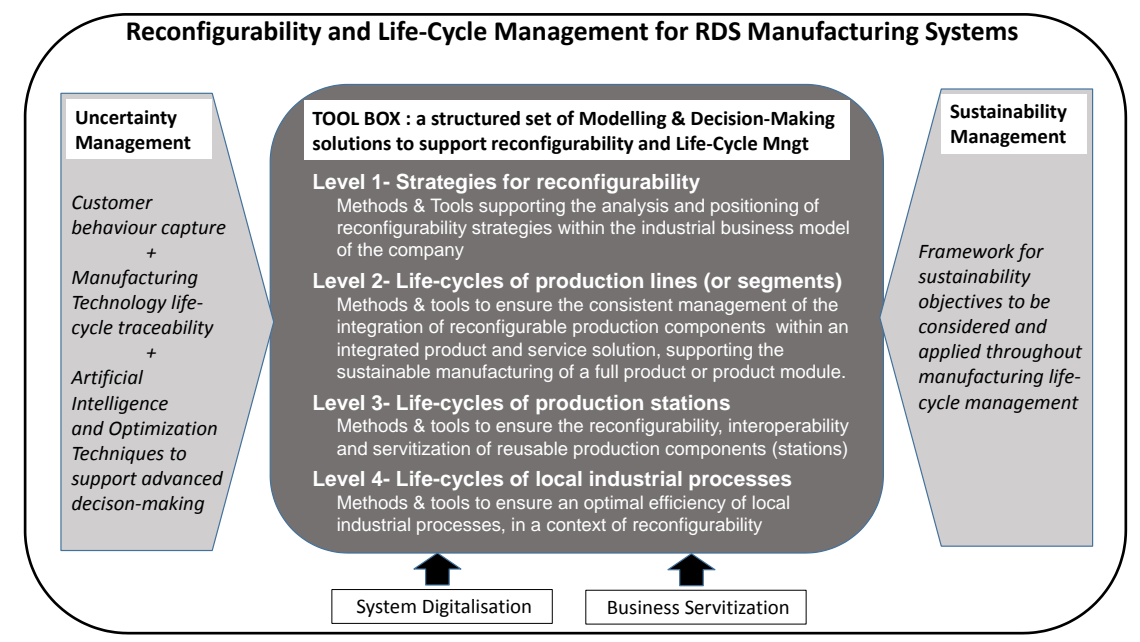

Fig. 1. Overview of reconfigurability framework for RDS manufacturing systems

The four levels of the framework correspond to a granularity decomposition of the manufacturing systems, leading to identify complementary reconfigurability and lifecycle management challenges. Level 1 addresses the strategical factors on reconfigurability, linked to business model definition. Levels 2 to 4 correspond to different levels of production system, where life-cycle management needs to be implemented. Each of these four levels gathers a set of decision-processes for which modelling and decision-aid solutions can be developed, in order to provide industry with a consistent decision-making toolset, making possible to address reconfigurability while maintaining a strong sustainability of the entire manufacturing system.

Of course this framework proposal requires to be validated in next research steps. A first validation proposed is a validation by expertise: capture the decision-making needs of several key users of RMS, to confront their precise decision-process requirements with the structured proposal. The second validation steps will be proof of concepts on pilot cases. This will be planned in next collaborative research phases.

\section{Conclusion and Perspectives}

This paper emphasized key research and industrial challenges for the next generation of RMS. Based on the analysis of current issues and trends, a conceptual framework was introduced with two main contributions: definition of the key notions of Reconfigurable Digitalized and Servitized Manufacturing Systems; and proposal of generic reconfigurability framework for RDS manufacturing systems. The framework is also structured as a research roadmap: next research steps consist in developing a detailed description of all the components of the framework, at the four levels proposed, validating the overall proposal, and then answering research gaps at each level. 


\section{References}

1. Wiendahl, H.-P., ElMaraghy, H. A., Nyhuis, P., Zäh, M. F., Wiendahl, H.-H., Duffie, N., Brieke, M.: Changeable Manufacturing: Classification, Design \& Operation. CIRP Annals 56(2), pp. 783-809 (2007).

2. Karl, F., Reinhart, G., Zaeh, M. F.: Strategic Planning of Reconfigurations on Manufacturing Resources. In: $45^{\text {th }}$ CIRP Conference on Manufacturing Systems, Procedia CIRP 3, pp. 608-613 (2012).

3. Liles, D. H., Huff, B. L.: A computer based production scheduling architecture suitable for driving a reconfigurable manufacturing system. Computers \& Industrial Engineering 19(1-4), pp. 1-5 (1990).

4. Koren, Y., Heisel, U., Jovane, F., Moriwaki, T., Pritschow, G., Ulsoy, G., Vann Brussel, H.: Reconfigurable manufacturing systems. Annals of the CIRP 48(2), pp. 527-540 (1999).

5. Koren, Y., Gu, X., Guo, W.: Reconfigurable manufacturing systems: Principles, design and future trends. Frontiers of Mechanical Engineering 13(2), pp. 121-136 (2018).

6. Delorme, X., Malyutin, S., Dolgui, A.: A multi-objective approach for design of reconfigurable transfer lines. In: $8^{\text {th }}$ IFAC Conference on Manufacturing Modelling, Management and Control MIM, IFACPapersOnLine 49 (12), pp. 509-514 (2016).

7. Andersen, A.-L., Brunoe, T. D., Nielsen, K., Rösiö, C.: Towards a generic design method for reconfigurable manufacturing systems-Analysis and synthesis of current design methods and evaluation of supportive tools. Journal of Manufacturing Systems 42, pp. 179-195 (2017).

8. Mittal, K. K, Jain, P. K.: An overview of performance measures in reconfigurable manufacturing system. In: $24^{\text {th }}$ DAAAM International Symposium on Intelligent Manufacturing and Automation, Procedia Engineering 69, pp. 1125-1129 (2014).

9. Rösiö, C., Aslam, T., Srikanth, K. B., Shetty, S.: Towards an assessment criterion of reconfigurable manufacturing systems within the automotive industry. In: International Conference on Changeable, Agile, Reconfigurable and Virtual Production, Procedia Manufacturing 28, pp. 76-82 (2019).

10. Uhlemann, T. H.-J., Lehmann, C., Steinhilper, R.: The Digital Twin: Realizing the Cyber-Physical Production System for Industry 4.0. In: $24^{\text {th }}$ CIRP Conference on Life Cycle Engineering, Procedia CIRP 61, pp. 335-340 (2017).

11. Boschert, S., Rosen, R.: Digital Twin-The Simulation Aspect. Mechatronic Futures-Challenges and Solutions for Mechatronic Systems and their Designers, pp. 59-74 (2016).

10. Seitz, K.-F., Nyhuis, P.: Cyber-Physical Production Systems Combined with Logistic Models-A Learning Factory Concept for an Improved Production Planning and Control. In: $5^{\text {th }}$ Conference on Learning Factories, Procedia CIRP 32, pp. 92-97 (2015).

13. Monostori, L., Kádár, B., Bauernhansl, T., Kondoh, S., Kumara, S., Reinhart, G., Sauer, O. et al.: Cyber-physical systems in manufacturing. CIRP Annals 65(2), pp. 621-641 (2016).

14. Hänsch Beuren, F., Gomes Ferreira, M. G., Cauchick Miguel, P. A.: Product-service systems: a literature review on integrated products and services. Journal of Cleaner Production 47, pp. 222-231 (2013).

15. Khan, M. A., Mittal, S., West, S., Wuest, T.: Review on upgradability-A product lifetime extension strategy in the context of PSS. Journal of Cleaner Production 204, pp. 1154-1168 (2018).

16. Medini, K., Boucher, X.: Configuration of Product-Service Systems value networks-Evidence from an innovative sector for sludge treatment. CIRP Journal of Manufacturing Science and Technology 12, pp. 14-24 (2016).

17. Bortolini, M., Galizia, F. G., Mora, C.: Reconfigurable manufacturing systems: Literature review and research trend. Journal of Manufacturing Systems 49, pp. 93-106 (2018).

18. Huang, A., Badurdeen, F., Jawahir, I. S.: Towards Developing Sustainable Reconfigurable Manufacturing Systems. In: $28^{\text {th }}$ International Conference on Flexible Automation and Intelligent Manufacturing FAIM, Procedia Manufacturing 17, pp. 1136-1143 (2018).

19. The US Department of Commerce: The International Trade Administration and The U.S. Department of Commerce's definition for Sustainable Manufacturing (2010), https://www.trade.gov/green/sm-101module.asp, last accessed 2019/03/25.

20. Garbie, I. H.: An analytical technique to model and assess sustainable development index in manufacturing enterprises. International Journal of Production Research 52(16), pp. 4876-4915 (2014).

21. Choi, Y.-C., Xirouchakis, P.: A holistic production planning approach in a reconfigurable manufacturing system with energy consumption and environmental effects. International Journal of Computer Integrated Manufacturing 28(4), pp. 379-394 (2015).

22. Bryman, A.: Social research methods. Oxford University Press, Oxford, New York (2012). 